\title{
INTEGRATED BUILDing INFORMATION MODELling (BIM) With Supply Chain and Feed-Forward CONTROL
}

\author{
Mojtaba Maghrebi ${ }^{1}$, Travis Waller ${ }^{1,3}$, Claude Sammut ${ }^{2}$ \\ ${ }^{1}$ School of Civil and Environmental Engineering, The University of New South Wales (UNSW), \\ Kensington NSW 2052, Australia, \{maghrebi,s.waller\}@unsw.edu.au \\ ${ }^{2}$ School of Computer Science Engineering, The University of New South Wales (UNSW), \\ Kensington NSW 2052, Australia, claude@cse.unsw.edu.au \\ ${ }^{3}$ National Information and Communications Technology Australia (NICTA), Sydney, Australia
}

\begin{abstract}
One of the major causes of delays in construction sites belongs to the delays in delivering materials. This paper introduces the integrated Building Information Modelling (BIM) model combined with a supply chain and a controlling system, along with its efficiency for alleviating the negative effects of delays caused by a lack of materials on construction sites. So, firstly the concept of feed-forward control is discussed as a prevention feature in a monitoring system. Then the integrating BIM model with a supply chain is introduced. Finally this case study has shown how the enhanced BIM model can incorporate the feed-forward control in order to decrease the risks of delays caused by a lack of materials in construction. Moreover, this case study might be used as a decision support system for managers to prevent a construction site from future delays by providing valuable information about the required materials in advanced.
\end{abstract}

KEYWORDS: building information modelling, supply chain, feed-forward control

\section{INTRODUCTION}

In terms of producing a product it can be said that a construction site is very similar to a factory. In a production line raw materials arrive at a workspace and after performing some tasks, the final production leaves the workspace. In a similar fashion construction sites add value to the raw materials during the operation process. So, the success of a construction project is very dependent on its supplied materials. This paper focuses on the supply chain process and the possible delays caused by a lack of materials on construction sites.

On the other hand, keeping the execution project on track on a construction site is an important goal for construction managers. As it was discussed before any delays in the supply process will lead to a decrease in the productivity rate during construction. 
Therefore, knowing about the reliability of a supply chain plan might help managers to make better decisions in advanced, which in some cases can possibly prevent the operation process from worse outcomes. The managers need sufficient information for each decision also implementing an automated system that will be able to alert the unexpected events may possibly decrease the managerial risks in construction.

One of the most significant characteristics of BIM is that it can provide the required information in an organized pattern. BIM tries to establish a comprehensive data-base from all constructional components. However, BIM initially only concentrates on gathering the required data for the execution process and in the literature there are only a few research papers that is regarding the enhancement of BIM with a supply chain $(1,2)$. However in literature it has not been clearly addressed how the efficiency of a supply chain can be increased in an automated fashion. This issue becomes more crucial for critical components where a delay in the supply chain will cause a delay in the whole construction process. The objective of this paper is to introduce a platform for integrating supply chain disciplines with BIM in order to decrease the construction delays caused by lack of materials. Moreover, in order to inform the managers in advanced about undesired issues in the supply chain, the concept of feed-forward control in cooperation with the enhanced BIM model is used.

In this paper firstly the concept of feed-forward control in construction is comprehensively discussed, secondly the BIM and conducted research in this area is reviewed. Then the proposed model for integrating BIM with supply chain is introduced and is tested in the case study. Subsequently the impacts of the introduced model and its possibilities in construction are discussed in the conclusion.

\section{FEED-FORWARD CONTROL}

In traditional models, the control and planning process are based on feedback information. It means that after an operational process the acquired information is sent to the control and planning stage, in this stage the actual characteristics of the project is compared with expected specifications. If the project is behind the desired goal then some adjustment actions will be made by authorized people to get the project back on track (Figure 1).

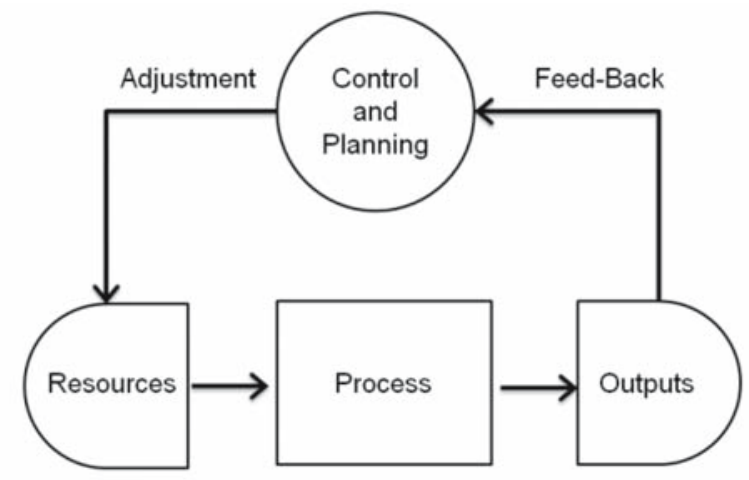

Figure 1. Traditional Process Planning and Control Model 
In the proposed control model (Figure 2) the resources should be assessed, before any activity, in the compatibility checking stage. The results of this assessment will be sent to the control stage by a feed-forward flow. This process reflects the actual circumstances in the supply chain. In the control stage the results of compatibility is compared with the expected outcomes which were embedded in the BIM. If there is any gap with these two, an adjustment action is required that must be applied in the BIM and via the BIM the resources will be revised. Furthermore, during the operation process the project will be monitored for controlling purposes. At the end of the operation process the project's outputs will also be evaluated and if there is any gap between the ideal output and the actual output, again the information will be sent to the control stage for further analysis and for possible replanning.

In this paper the introduced controlling model is used to identify the possible challenges as early as possible. The mangers will potentially have enough time to find a way to solve the highlighted problems because these circumstances defiantly are better than the situations that they just faced with problem. However the introduced controlling model needs to be fed the updated information at each moment

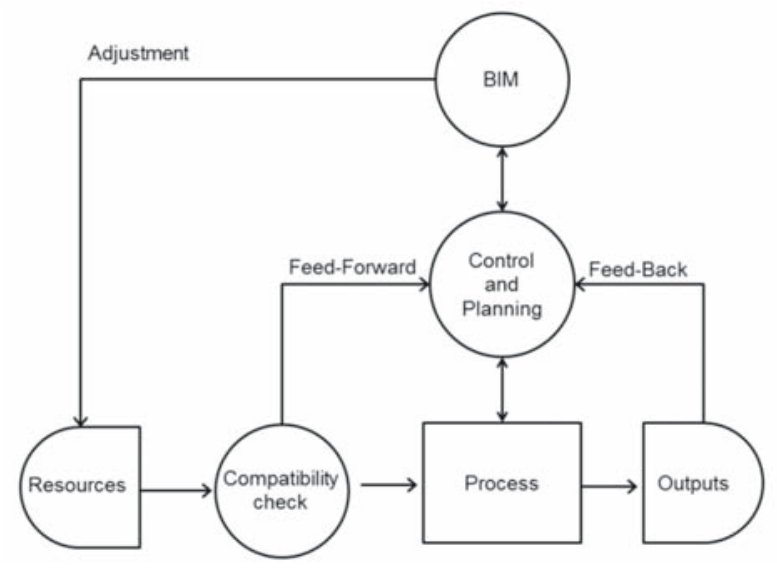

Figure 2. Process Control Model

\section{BUILDING INFORMATION MODELLING (BIM)}

The concept of BIM was coined by Charles M. Eastman at Georgia Tech (3) and from 1970s he has worked on an extension of the BIM. His main research focuses on product modeling, data modeling and information modeling in engineering (4-14). The concept of Building Information Modeling means building a building virtually prior to building it physically, in order to work out problems, and simulate and analyze potential impacts (15). BIM is an objectoriented data-base which covers attributes and roles of all construction components. Moreover, BIM can be used as a tool for generating and managing data during the life cycle of structures. BIM covers building geometry, spatial relationships, geographic information, and quantities and properties of building components (11, 15-19). Meadati (2007) (20) expresses that BIM is only used at an early stage and tries to integrate BIM by the 3D as-built model to increase the capability of BIM during the maintenance period. In terms of automation in BIM, several scholars have worked on this area, and mostly, accuracy and reliability of the model were the 
main concerns (12). Translation of design to a computational form were studied by several scholars such as $(17,21)$. Grilo (2010) (22)expresses that a large amount of data is gathered by BIM but the access to this data-base is not facilitated then he attempted to improve the interoperability of data in a construction project during its lifetime by the standardization of the shared data. As it was discussed before, most of research in BIM was devoted to the design and execution process and this issue were addressed in the literature specially in the review papers of Succar (23)). However, in this paper it is focused on integrating BIM with a supply chain and its application in construction. BIM is hired in this paper as the core of the information in providing the required information to the authorized people involved in the construction process. Then an enhanced BIM with a supply chain is used with a feed-forward control in order to decrease the negative effects of delays caused by a lack of materials in construction.

\section{METHODOLOGY}

It is expected that by implementing the proposed controlling model (Figure 1) and the feedforward controls the problems in the supply chain can be automatically detected upfront. So, first of all the BIM needs to be enhanced with a supply chain. For this purpose the proposed model is depicted in (Figure 3). BIM is an objected oriented database and information can be added to BIM just by assigning it to the construction components. Already information about the specifications of materials, cost and time are assigned to components. Now the supply chain properties can be assigned to the components. BIM supply chain contains essential information from the entire the supply process for example from the end of the design process when the required materials are defined till to the date that is expected from suppliers to deliver the materials to the site. The whole of this process is illustrated at the bottom of (Figure 3). In other words, this information for each component is a list of milestones and time slots that were scheduled by planners to ensure that the required materials for operations would be at the site before the commencement of operations. After adding these properties to each component a 3D BIM model can be built. By having all components together, the process planning can now be added which includes the execution plan. It categorizes the components into the groups that are known as the construction tasks. All components of a task must be executed together. Other relationships between tasks such as precedence and other network relations among the tasks are defined in this stage. The last feature that must be added to the model is time. This attribute is assigned to tasks that were defined in the previous stage. Subsequently, an enhanced BIM model with a supply chain is created. Based on the other information provided the BIM model can be 4D, 5D ..., and $\mathrm{nD}$. Consequently, with this model producing different reports and specific plans are straightforward for planners. This paper only focuses on supply chain plans rather than other possible outputs from the model. A comprehensive BIM model does not merely work in a construction project because the information in construction is very uncertain and might be changed at any time. For alleviating this dynamic behavior the concept of feed-forward control that was discussed previously can potentially reduce the possible risks of unavailable materials on construction sites for as long as it is incorporated with updated data achieved by an enhanced BIM data base. The supply chain properties provide several milestones for each component that need to be checked at the defined dates. In practice, doing this job manually is cumbersome because there are many components in a project that are supplied from different resources and different suppliers, so, it needs to be done automatically. 


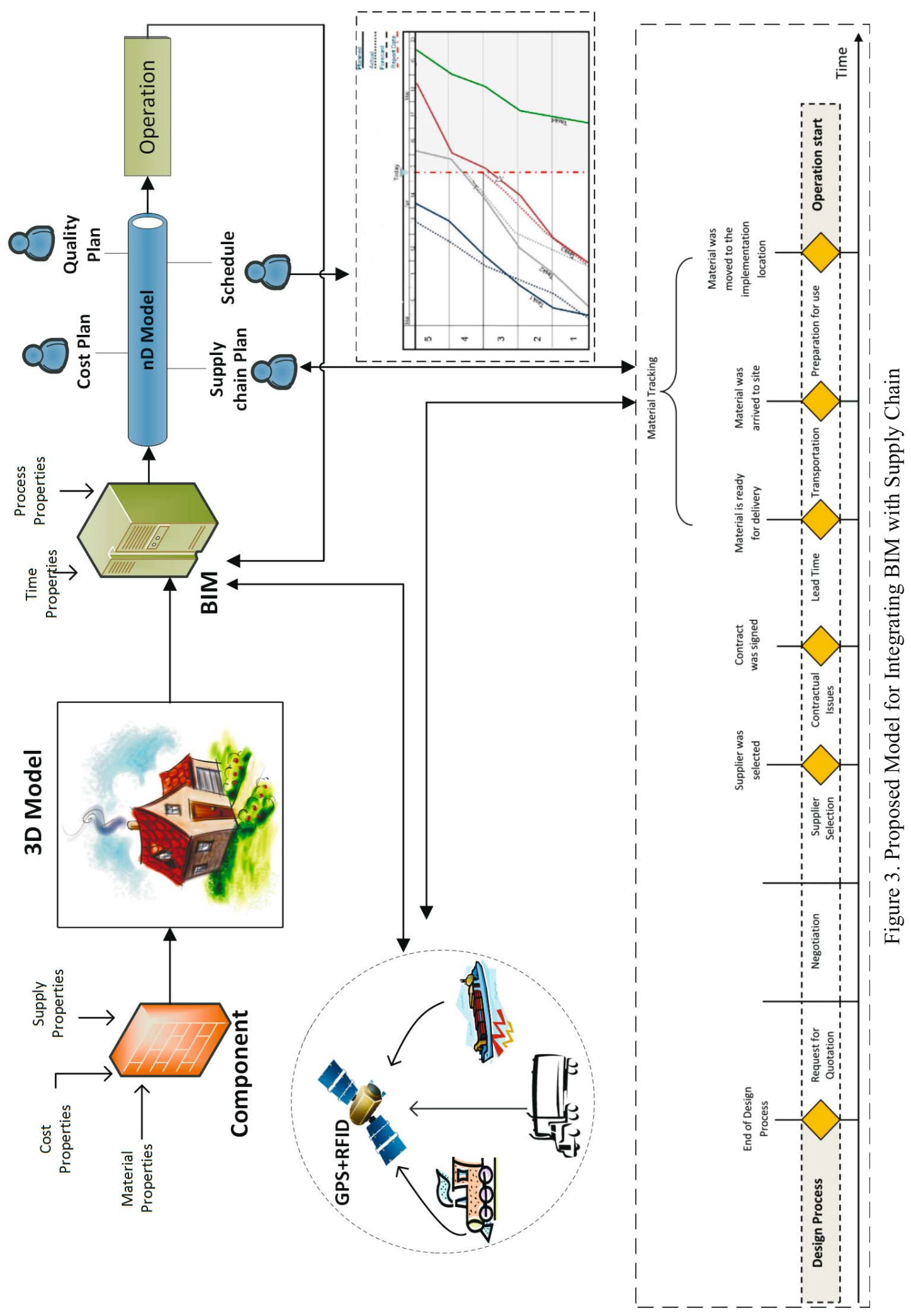


It should be noted that Radio-Frequency Identification (RFID) and Global Positioning System (GPS) can be applied in the proposed model. After checking each milestone the updated information will be controlled with the supply plan. If there is any positive or negative gap between the expected outcomes and the actual outcomes of a component, then updates will be sent to the control stage where it will be reviewed by authorized people. Sometimes delivering materials to a site sooner than the plan can be a challenge, where the storage space for raw materials is very limited. So, receiving material sooner than its planned date is usually not a desired outcome. Consequently, the materials must be on site at the scheduled date with minimum delay or sooner delivery. Taking advantage of updates regarding the materials creates opportunities for planners to adjust the operation plan under the new circumstances. This ability will possibly prevent the construction process from delays caused by unavailable materials.

\section{CASE STUDY AND DISCUSSION}

In order to test the introduced model, a construction project in Sydney area was selected. The project comprises of an accommodation building with 8 stories located in a university with very limited space for storing the raw materials. Also the contractor is under pressure from university to deliver the project on time. Due to the economic considerations the concrete piles for this project were ordered from China. However, the long distance between the prefab factory in China and the construction site in Sydney is a big challenge for managers. Moreover, the critical issue is that the piles must be placed in foundation and all other construction task will be run after finishing the task. So any delay in piles delivery defiantly will lead to increasing the delays for the project. In this construction site, it wouldn't be appropriate to have an expectation to receive the piles according to schedule. They must be certain that the pile will be delivered to the site on the exact planned dates with minimum variability. We implemented our model on this project based on the overview that is illustrated in (Figure 4).

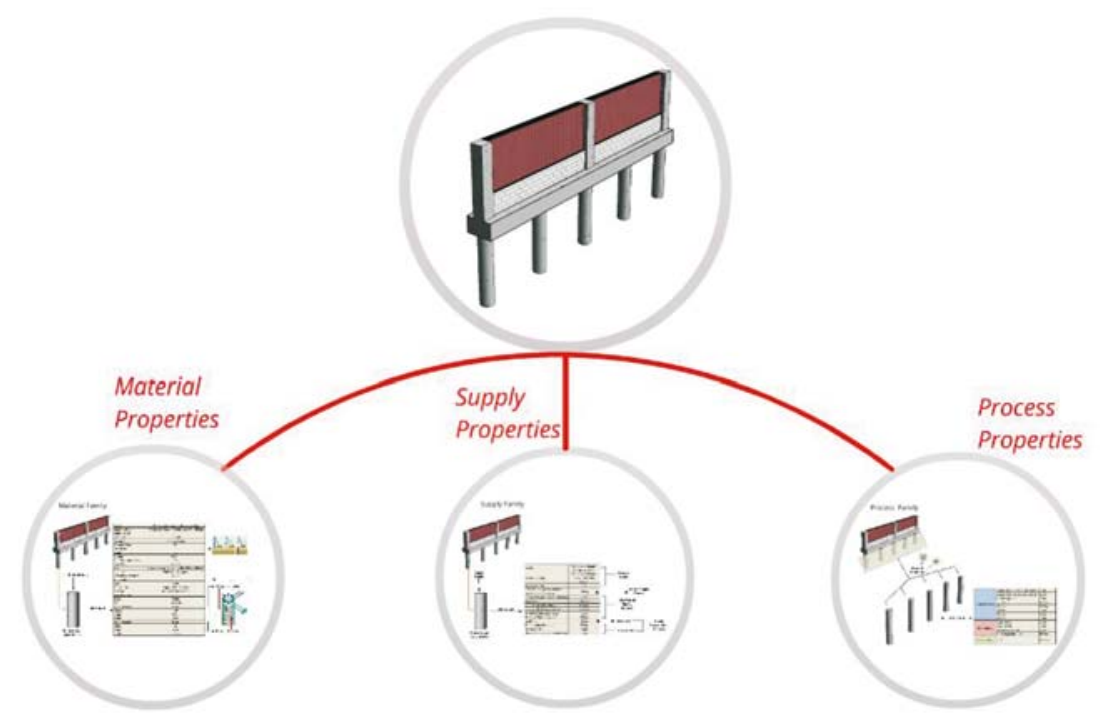

Figure 4. Overview of Steps that is Needed for Enhancing BIM with Supply Chain. 
Firstly, the material properties were assigned to the piles (Figure 5) which includes all required information about the sizes, geometries, and quantity of required materials. As the cost of a pile is fixed then the cost feature is embedded in the material properties and linked to the cost plan.

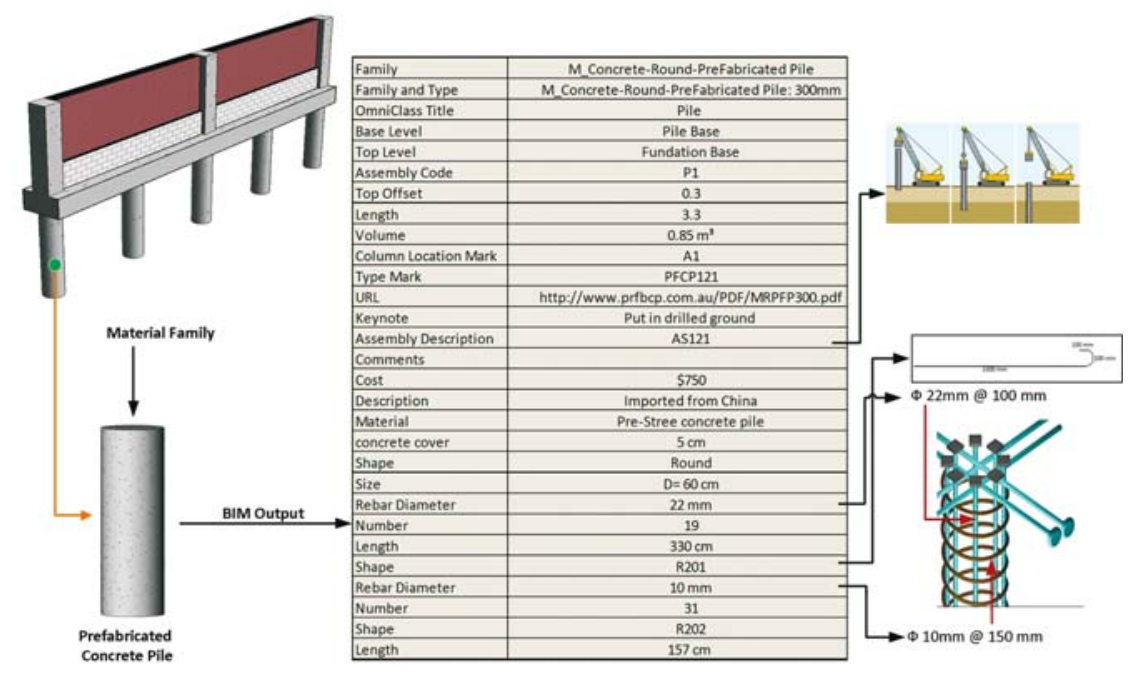

Figure 5. Structure of Material Properties for Piles

Secondly, supply properties were defined for piles (Figure 6). All the defined periods are in the negative because they were calculated relative to the date that the construction task is in need of components. Then after adding the time properties to the tasks, the supply chain plan will be automatically calculated based on the supply properties and the given date by the time properties.

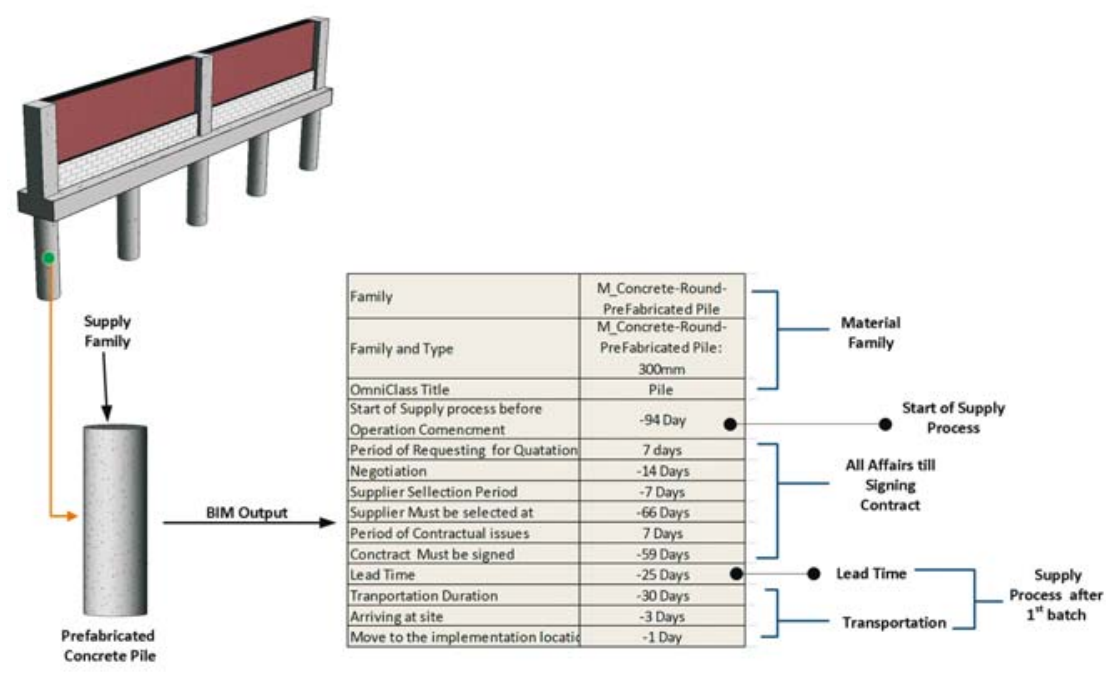

Figure 6. Structure of Supply Properties for Piles 
Finally, the process properties were set in BIM (Figure 7). At this step, rather than defining the execution process, all the other required resources that were not covered in material properties are estimated and embedded in the BIM model.

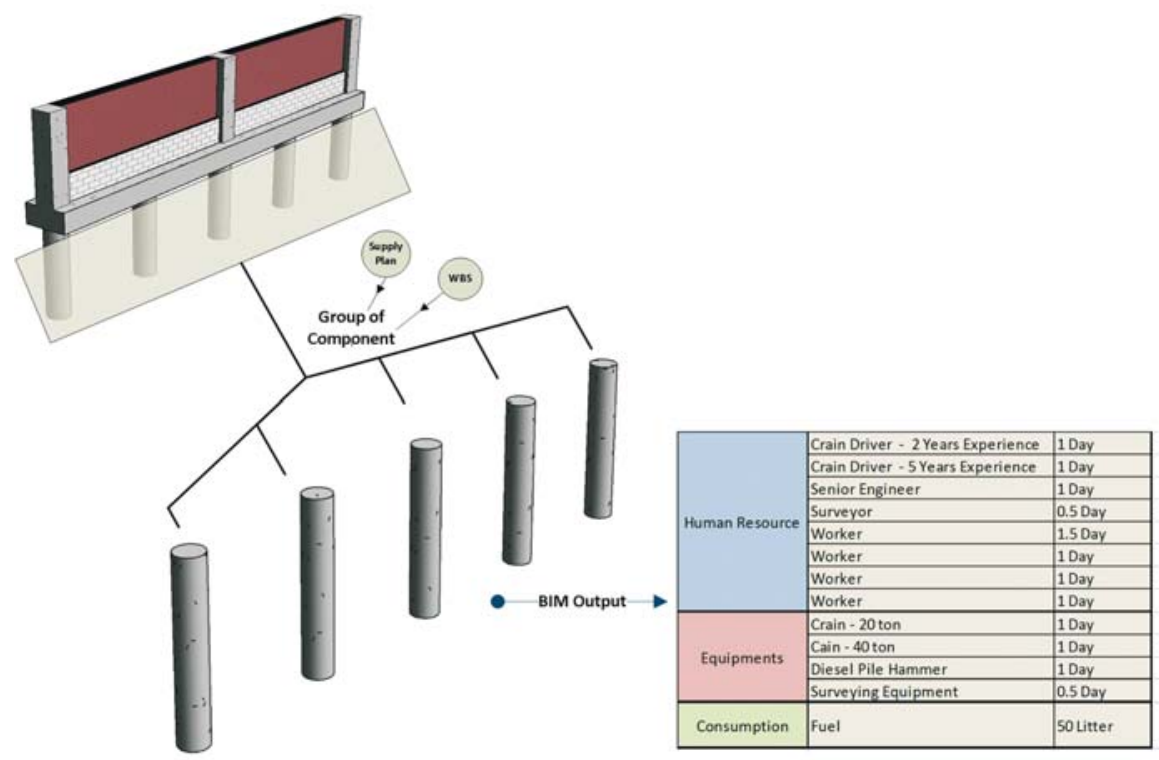

Figure 7. Structure of Process Properties for a Set of Piles

The BIM model was then enhanced with supply features. However, a well-founded data base will not merely work, since it needs to be integrated in to the planning system in order to control the supply plan. In automatically compiling the supply chain data, the importance of using RFID and GPS was suggested to the construction managers. RFID can ease the identifying process of each component and GPS provides the actual location of each component. In this scenario, it was expected that a series of piles were to be delivered to the site on the 28th of September. However, due to the shipping period and the custom affairs it was planned to ship the piles at least one month earlier from China. In analyzing the current location of piles on the 10th of September it was realized that they will not be delivered to the site on the expected date. Studies show that in typical situations the pile will be delivered to the site with at least one weeks delay (Figure.8).

At this point in time it was a serious concern for construction managers, however, they identified this problem 18 days prior to the date of delivery, so there was enough time for two major adjustments. The first adjustment was in decreasing the negative effects of a lack of piles on site by preplanning the execution process. This may include compressing the duration of the rest of the tasks or swapping the flexible tasks in a schedule to compensate for the expected delay. If compressing is to be selected, then no activity will take place on the site after the 1st of October (the task commencement date) and the site will be closed for a week. So, compressing the rest of the tasks is one opportunity for managers to keep the project on track. Conversely, if swapping within the execution plan is to be selected then the manager can tart other execution processes sooner than scheduled, but with potential difficulty. 


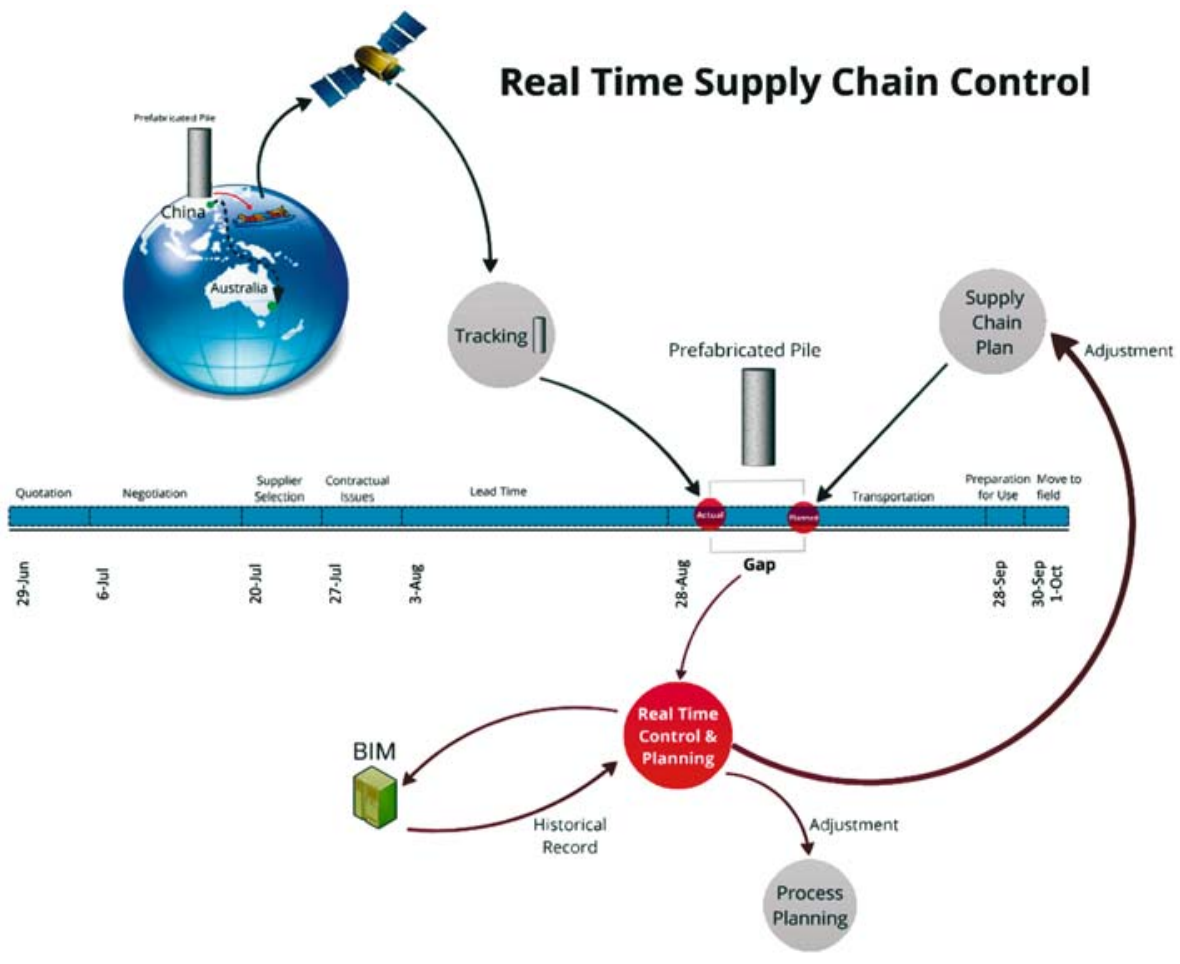

Figure 8. The Controlling Process for the Piles

The second adjustment that managers will perform will be to revise the supply chain process, in which will help them find possible obstacles. Then it is expected that resolving these problems will assist managers to increase the reliability of the supply chain. So, this kind of supply chain control, can control the negative effects of delays caused by a lack of materials and provides valuable information for managers in advanced in order to finding the possible ways to control the unexpected events occurring on construction sites.

\section{CONCLUSION}

The unexpected delays caused by a lack of materials on construction sites are a big challenge for managers. In this paper the concept of feed-forward control was applied with BIM in order to establish a platform that will be able to control the supply chain process automatically. BIM was selected in this paper as a central database, so rather than material, cost and time properties that are already embedded in BIM model, the supply chain properties also added to the BIM. The supply chain properties consist of a set of periods of time in a supply chain processes that are defined relative to the commencement date of the task requiring the components. Then based upon this data and the starting dates, which are defined by time properties, the supply chain plan for each component can be calculated automatically. Finally, this case study has shown how the concept of integrating BIM with a supply chain can provide valuable information to managers in advanced, which can lead to alleviate the negative effects of a lack of materials for the whole construction process. 


\section{AcknOWLedgement}

The authors would like to thank the technical committee of Creative Construction Conference 2013 for inviting this paper to the special issue (YBL Journal of Built Environment) and also the authors appreciate the reviewers for their constructive comments.

NICTA is funded by the Australian Department of Communications and the Australian Research Council through the ICT Centre of Excellence program.

\section{REFERENCES}

[1] Sacks R, Radosavljevic M, Barak R 2010 Requirements for building information modeling based lean production management systems for construction. Automation in Construction 19:641-655

[2] Taylor J, Bernstein P 2009 Paradigm Trajectories of Building Information Modeling Practice in Project Networks. Journal of Management in Engineering 25:69-76

[3] Eastman C, Teicholz P, SaCks R, Liston K 2008 Frontmatter. In: BIM Handbook: John Wiley \& Sons, Inc.; i-xiv

[4] Eastman CM, Bond AH, Chase SC 1991 Application and evaluation of an engineering data model. Research in Engineering Design 2:185-207

[5] Eastman CM, Chase SC, Assal HH 1993 System architecture for computer integration of design and construction knowledge. Automation in Construction 2:95-107

[6] Eastman CM 1994 A data model for design knowledge. Automation in Construction 3:135-147

[7] Eastman CM, Siabiris A 1995 A generic building product model incorporating building type information. Automation in Construction 3:283-304

[8] Khedro T, Eastman C, Junge R, Liebich T 1996 Translation methods for integrated building engineering. Computing in Civil Engineering (New York):579-585

[9] Eastman C, Sacks R, Lee G 2003 Development and implementation of advanced it in the North American precast concrete industry. Electronic Journal of Information Technology in Construction 8:247-262

[10] Eastman C, Wang F, You SJ, YANG D 2005 Deployment of an AEC industry sector product model. CAD Computer Aided Design 37:1214-1228

[11] Lee G, SACKs R, Eastman CM 2006 Specifying parametric building object behavior (BOB) for a building information modeling system. Automation in Construction 15:758-776

[12] Lee J-K, Eastman CM, Lee J, Kannala M, Jeong Y-s 2010 Computing walking distances within buildings using the universal circulation network. Environment and Planning B: Planning and Design 37:628-645

[13] Lee JK, Eastman CM, Lee J, Kannala M, Jeong YS 2010 Computing walking distances within buildings using the universal circulation network. Environment and Planning B: Planning and Design 37:628-645

[14] Sacks R, Kaner I, Eastman CM, Jeong YS 2010 The Rosewood experiment - Building information modeling and interoperability for architectural precast facades. Automation in Construction 19:419-432

[15] Sмiтh DK, TARdiF M 2009 Building Information Modeling: A Strategic Implementation Guide for Architects, Engineers, Constructors, and Real Estate Asset Managers: John Wiley \& Sons

[16] Eastman C, Teicholz P, Sacks R, Liston K 2011 BIM Handbook: A Guide to Building Information Modeling for Owners, Managers, Designers, Engineers and Contractors: Wiley

[17] Elvin G 2007 Integrated Practice in Architecture: Mastering Design-Build, Fast-Track, and Building Information Modeling: John Wiley \& Sons

[18] Underwood J, IsIKDag U 2009 Handbook of Research on Building Information Modeling and Construction Informatics: Concepts and Technologies: IGI Global

[19] Kymmele W 2008 Building Information Modeling: Planning and Managing Construction Projects with 4D CAD and Simulations (McGraw-Hill Construction Series): McGraw-Hill

[20] Meadati PK 2007 Integration of construction process documents into building information modeling THE Univeristy of Nebraska-Lincoln

[21] YANG QZ, XU X 2004 Design knowledge modeling and software implementation for building code compliance checking. Building and Environment 39:689-698

[22] Grilo A, Jardim-Goncalves R 2010 Value proposition on interoperability of BIM and collaborative working environments. Automation in Construction 19:522-530

[23] Succar B 2009 Building information modelling framework: A research and delivery foundation for industry stakeholders. Automation in Construction 18:357-375

[24] TALAMON, A., Adapting building sector to climate change: The case of Hungary, (2013) IYCE 2013 - 4th International Youth Conference on Energy, art. no. 6604157, 